\title{
Turismo y vulnerabilidad social. Reflexiones para algunos casos latinoamericanos
}

\author{
Zulma Vianchá-Sánchez ${ }^{* *}$ \\ Humberto Rojas-Pinilla ${ }^{* * *}$ \\ Miguel Ángel Barrera-Rojas ${ }^{* * *}$
}

\begin{abstract}
* Esta investigación forma parte de la Beca de Formación de Alto Nivel para el Departamento de Boyacá, financiada por el Ministerio de Ciencia, Tecnología e Innovación de Colombia y el Departamento de Boyacá. Este artículo es uno de los resultados del proceso de investigación adelantado por Zulma Vianchá del Doctorado en Estudios Ambientales y Rurales de la Universidad Javeriana dirigido por Humberto Rojas Pinilla y de la pasantía realizada durante el primer semestre de 2020 en la Universidad de Quintana Roo.

** Investigadora del Centro Regional de Gestión para la Productividad e Innovación de Boyacá CREPIB. Candidata al Doctorado en Estudios Ambientales y Rurales de la Pontificia Universidad Javeriana. Magíster en Diseño y Gestión de Procesos por la Universidad de La Sabana, Colombia. Correo electrónico: zuvisanchez@gmail.com. https://orcid.org/0000-0001-6371-934

*** Profesor asociado al Departamento de Desarrollo Rural y Regional de la Facultad de Estudios Ambientales y Rurales de la Pontificia Universidad Javeriana-Bogotá. Doctor en Ciencias Sociales y Humanas de la Pontificia Universidad Javeriana. Magíster en Development Studies (Rural and Agricultural Development) del Institute of International Studies, The Hague, Netherlands. https://orcid. org/0000-0002-8957-1787

${ }^{* * * *}$ Profesor investigador en la División de Ciencias Políticas y Económicas de la Universidad de Quintana Roo unidad académica Chetumal, México. Doctor en Geografía por la Universidad de Quintana Roo, México. Magíster en Desarrollo Regional por El Colegio de la Frontera Norte. https:// orcid.org/0000-0002-9240-7646
\end{abstract}

Fecha de recepción: 30/05/2020. Fecha de aceptación: 21/05/2021. 


\title{
Turismo y vulnerabilidad social. Reflexiones para algunos casos latinoamericanos
}

\section{Resumen}

El turismo es considerado tanto una salida a la pobreza como un generador de contextos de vulnerabilidad social, al desarrollarse en condiciones territoriales diversas. En Latinoamérica, las estructuras sociales e inequidades elevan la vulnerabilidad de las comunidades anfitrionas, razón por la cual los impactos del turismo no siempre son beneficiosos. Este artículo analiza los procesos de transformación que emergen como resultado de la configuración de los destinos turísticos y sus complejas interrelaciones e impactos. La revisión se realizó a partir de búsquedas de casos en países latinoamericanos en la base de datos SCOPUS. A partir de ella, se seleccionó un caso en México y uno en Colombia para profundizar en dichas transformaciones. El estudio permitió identificar que los impactos más referenciados en las investigaciones son negativos, particularmente relacionados con la destrucción y pérdida de resiliencia de los ecosistemas, el aumento de la vulnerabilidad social de los medios de vida de las comunidades locales, el aumento de conflictos por el acceso y uso de recursos naturales y la desigualdad en la distribución de los costos y beneficios del turismo.

Palabras clave: turismo, estructuras sociales, vulnerabilidad social, Latinoamérica.

\section{Tourism and social vulnerability. Reflections for some Latin American cases}

\begin{abstract}
Tourism is considered a way out of poverty and a generator of contexts of social vulnerability because it develops in diverse contexts and territorial conditions, which generate results ambivalent. In Latin America, social structures and inequities increase the vulnerability of host communities, which is why the impacts of tourism are not always beneficial. This article analyzes the transformation processes that emerge because of the configuration of tourist destinations and their complex interrelationships and impacts. The review was carried out from searches of cases in Latin American in the SCOPUS database, then a case in Mexico and Colombia was selected to deepen these transformations. The study made it possible to identify that the impacts most referenced in the research are negative, particularly related to the destruction and loss of resilience of ecosystems, the increase in the social vulnerability of the livelihoods of local communities, the increase in conflicts due to the access and use of natural resources and inequality in the distribution of costs and benefits of tourism.
\end{abstract}

Keywords: tourism, social vulnerability, Latin America. 


\section{INTRODUCCIÓN}

El turismo evidencia las características y contexto de un lugar, su grado de «desarrollo o subdesarrollo», las desigualdades internas, formas de vivir, lo atractivo y lo repulsivo (Cordero, 2006). Quienes promueven el turismo tratan de presentar los destinos en su aspectos más positivos; en este proceso, algunos elementos territoriales se desdibujan por concentrarse los análisis en los requerimientos técnicos de un sector económico en fuerte crecimiento incorporando solo elementos relacionados con la prestación de servicios (diversión, bienestar, nuevas experiencias, etcétera), sin profundizar en las diversas interacciones presentes en el territorio y determinar tanto la sostenibilidad de la actividad turística en el largo plazo como la distribución de los costos y beneficios entre los actores involucrados (Gascón y Ojeda, 2014; Rojas, 2009).

El turismo se promociona como una estrategia para aliviar la pobreza; sin embargo, sus efectos pueden ser desiguales. Mientras algunos consideran que el turismo aporta a la solución de problemas territoriales generando ingresos diversificados, divisas, inversión y vínculos intersectoriales con los sectores transporte, suministro de alimentos, agricultura y pesca; genera empleo, especialmente para mujeres, jóvenes y grupos minoritarios; promueve la valoración y uso sostenible del entorno natural y cultural (Ashley y Goodwin, 2007; OMT, 2001; Schulte, 2003; Tao y Wall, 2009; UNWTO, 2017). Para otros, al impulsar la migración y requerir una gran especialización de la oferta turística que hace poco viables las iniciativas comunitarias, genera dependencia y propicia la erosión de los activos de las comunidades elevando la posibilidad de la población local de caer en la trampa de la pobreza, aumenta las brechas y la desigualdad, y favorece contextos de vulnerabilidad de las poblaciones con menor acceso a recursos del territorio (Buades et al., 2012; Cañada y Gascón, 2007; Gascón y Milano, 2017; Rivera y Rodríguez, 2012; Serge, 2010; Tao y Wall, 2009; Torres, 2003; Piketty, 2020).

Es por esta razón que el análisis de las complejas relaciones entre el auge del turismo y la vulnerabilidad de las comunidades receptoras se constituye hoy por hoy en un elemento central. Los estudios sobre vulnerabilidad y turismo han sido abordados desde el ámbito de la sociología del turismo y desde los estudios sobre la desigualdad y exclusión social; sin embargo, es evidente la ausencia de análisis que hagan referencia a las características específicas de la vulnerabilidad social en las zonas turísticas (Gallego, 2015).

Quienes han abordado el análisis de las relaciones entre vulnerabilidad y el impacto del turismo evidencian la degradación social de los destinos, especialmente en cuanto a las condiciones de trabajo, vida y vivienda de los trabajadores. Es claro que el potencial del turismo para transformar las estructuras locales pone en juego 
la supervivencia del propio destino turístico, lo que está relacionado con la estrecha vinculación al gran capital, los mercados y sistemas financieros globales, unido a las alianzas políticas. En general, se prefiere abordar el tema de la vulnerabilidad desde el cambio climático particularmente asociado con el concepto de riesgo, sensibilidad, fragilidad, resistencia y adaptabilidad. Este documento aborda el análisis desde las relaciones entre el auge del turismo y la vulnerabilidad social.

\section{Vulnerabilidad social}

La vulnerabilidad es un fenómeno multidimensional que depende: (i) del contexto social, institucional, político y económico; (ii) de la capacidad de grupos, comunidades y dinámicas individuales; (iii) de los tipos y valores de amenazas existentes, y (iv) de la escala de estudio (Climent, 2001; Foschiatti, 2009; Lampis, 2009).

La vulnerabilidad se ha analizado desde cuatro grandes categorías: (i) riesgo y amenaza, asociados a la exposición, peligro sensibilidad o susceptibilidad a una amenaza o dańo, dada por la incapacidad interna, fragilidad o indefensión de reaccionar o resistir de forma adecuada cuando la amenaza se concreta; (ii) resiliencia, asociada a la imposibilidad para recuperar las condiciones normales de vida, o débil capacidad de adaptación, diversidad o trasformación de los sistemas socioecológicos para absorber perturbaciones, mantener sus funciones, renovarse y reorganizarse; (iii) derecho, relacionada con los fallos asociados a las teorías del cambio social, la autonomía y la toma de decisiones; (iv) capacidades, centradas en el análisis de la disponibilidad y capacidad de movilización de activos y recursos que disponen los individuos, hogares o comunidades para su desempeño social (Adger, 2006; Busso, 2001; Chambers y Conway, 1991; Foschiatti, 2009; Kaztman y Filgueira, 1999; Lampis, 2009; Moser, 1998; Turner et al., 2003).

La noción de vulnerabilidad social asocia una serie de elementos y variables relacionando presiones e interacciones sociales de lo global a lo local. En lo global se relaciona con las estructuras sociales, institucionales, políticas y económicas; en lo regional, están los procesos de cambio, como el auge del turismo, el crecimiento de la población, urbanización y densificación, la degradación ambiental, la falta de ética, etcétera. Y en lo local, se trata de condiciones de inseguridad y fragilidad social de las comunidades, hogares e individuos, determinados por su disponibilidad y capacidad de movilización de activos y recursos (Blaikie et al., 1996; Busso, 2001).

\section{Turismo y vulnerabilidad social en el contexto latinoamericano}

El turismo requiere un contexto adecuado, que permita una articulación apropiada a las características territoriales del lugar donde se encuentran atractivos que motivan 
a la demanda turística y el proceso de convertirlo en un producto turístico; es decir, la combinación de atractivos, servicios, infraestructura y actividades en torno a un tema de interés, como la naturaleza, historia, cultura, deporte, descanso, etcétera, que determina los tipos específicos de demandas: turismo gastronómico, ecoturismo, turismo rural, etcétera (Boullón, 2006; Naciones Unidas y OMT, 2010).

Para el contexto latinoamericano, si bien las estadísticas mostraron un crecimiento económico esporádico, este no se ha reflejado en cambios positivos en los niveles de bienestar social e igualdad (CEPAL, 2015; Herrera et al., 2017). La región continúa presentando condiciones poco favorables para el desarrollo del turismo, dada la persistencia de pobreza estructural, vulnerabilidad social y exclusión del grueso de la población.

La vulnerabilidad de las comunidades locales en Latinoamérica se evidencia en numerosos elementos; entre ellos, carencias en el acceso a servicios básicos como agua potable, energía y alcantarillado o baja calidad y cobertura de los servicios de educación y protección social (Naciones Unidas, 2017). Hay enormes desigualdades en la distribución de los ingresos, alta concentración de la propiedad rural, baja distribución de los beneficios de la modernización, así como poco acceso a infraestructura productiva y social (FAO, 2017; PNUD, 2011), todo ello en un contexto de fuertes transformaciones derivadas de una veloz urbanización, alto costo de la tierra, fuertes dinámicas de acaparamiento, sumado a la presencia de poblaciones sin acceso a recursos productivos que, además, sufren la incertidumbre del cambio climático y están articuladas de forma desfavorable a los mercados (FAO, 2017).

Es importante tener en cuenta que, de una parte, muchas de las iniciativas turísticas se ponen en marcha en contextos territoriales desfavorables, con predominancia de poblaciones con bajos niveles de acceso y control a los activos del territorio (Tao y Wall, 2009), baja regulación y poca presencia del Estado y las instituciones, corrupción e impunidad, o garantías civiles, con alta competencia, escasas posibilidades de ofrecer productos diferenciados y bajo poder de negociación y de representatividad, lo cual impide ampliar las oportunidades en los ámbitos del mercado (Gascón y Milano, 2017).

Por otra parte, las transformaciones generadas por el auge del turismo suelen ser más profundas y tener más repercusiones en espacios rurales, al relacionarse con elementos como las formas como se toman las decisiones y se asignan los recursos para la actividad turística, como corresponde a la tierra, agua, atractivos, infraestructura, alimentos, energía, fuerza de trabajo, etcétera, y la magnitud e intensidad en el uso de estos recursos en función de la escala y características que adquiera el desarrollo turístico, así como los conflictos que acompañan dichas decisiones y las nuevas interacciones entre naturaleza y sociedad (Gascón y Milano, 2017; Maguigad, 2013; Vianchá, 2021). 
Queda claro que los desarrollos turísticos generan fuertes transformaciones políticas, sociales, económicas, ecológicas y culturales, y los más vulnerables son los más afectados. De acuerdo con las cuatro categorías, tal como se ha analizado la vulnerabilidad, el desarrollo del turismo puede elevar las brechas, poner en marcha o agudizar diferentes tipos de trampas de la pobreza, dependiendo del contexto territorial, las estructuras sociales presentes, y sus formas de articulación en distintas escalas.

En efecto, puede propiciar despojos territoriales o elevar riesgo de perder o erosionar activos fundamentales para la configuración de los medios de vida de las comunidades, como corresponde a los recursos tierra y agua fundamentales para sus labores productivas y reproductivas. Erosionar, limitar el acceso o privatizar recursos antaño de uso común, como ejidos, manglares, cenotes, bosques, playas y zonas de pesca, etcétera. Asimismo, puede transformar de una manera radical hábitats naturales y ecosistemas de los que las comunidades tradicionales han dependido muy estrechamente para sobrevivir. Todo esto se une a la muy limitada posibilidad de incidir en las decisiones de política sobre los recursos presentes en sus territorios, por lo regular tomadas desde el centro y unilateralmente. A ello se suma, por lo regular, un contexto con pocas posibilidades de agenciar los recursos disponibles, participar o competir en los mercados, ya sea por limitaciones de acceso, restricciones sanitarias, pruebas de inocuidad de sus productos, permisos, licencias, etcétera, o por competencia desleal en virtud de las economías de escala (Amelung et al., 2016; Buckley, 2011; Comerio y Strozzi, 2019; Gössling, 2002; Gössling y Peeters, 2015; Tang, 2015; Vianchá, 2021).

Teniendo en cuenta todo lo anterior, este artículo hace una revisión de las transformaciones que emergen como resultado del proceso de configuración de un destino turístico y sus complejas implicaciones e impactos, considerando que es un proceso que dinamiza profundas transformaciones que a menudo elevan la vulnerabilidad social. La revisión de estas transformaciones, sus implicaciones e impactos se realizó a partir de búsqueda de casos publicados en la base de datos SCOPUS en países latinoamericanos. Asimismo, se seleccionaron dos estudios de caso: uno en México y otro en Colombia, con el fin de profundizar en las características, tipos de transformaciones y sus implicaciones de manera específica.

\section{Metodología}

La metodología se inspiró en el proceso de mapeo sistémico (Centre for EvidenceBased Conservation, 2010), que busca describir evidencias relevantes de un tema dado, con preguntas abiertas, haciendo síntesis de la información. A continuación, se menciona el proceso que se siguió para la revisión. 
a. Definir el alcance. Esta revisión buscó indagar acerca de las implicaciones en términos de vulnerabilidad social y pobreza como resultado de las dinámicas de configurar un destino turístico. La pregunta que orientó la búsqueda de documentos fue: ¿qué implicaciones en términos de vulnerabilidad social y pobreza ha tenido el proceso de configurar un destino turístico?

b. Definir la estrategia de búsqueda. La búsqueda de información se realizó en la base de datos SCOPUS y en Google Academics, usando los términos específicos de la tabla 1.

c. Selección de artículos para el análisis. Al terminar la búsqueda se leyeron los 133 títulos y resúmenes y se seleccionaron 81 investigaciones. Se utilizaron como criterio de selección documentos que presentaran procesos de transformación impulsados por el turismo.

Tabla 1 Elementos de la ecuación de búsqueda

\begin{tabular}{cccccc}
\hline Título & $\begin{array}{c}\text { Operador } \\
\text { booleano }\end{array}$ & Palabras clave & $\begin{array}{c}\text { Operador } \\
\text { booleano }\end{array}$ & $\begin{array}{c}\text { Título, palabra } \\
\text { clave, resumen }\end{array}$ & $\begin{array}{c}\mathrm{N}^{\circ} \text { de artículos } \\
\text { encontrados }\end{array}$ \\
\hline Tourism & AND & $\begin{array}{c}\text { Países } \\
\text { latinoamericanos }\end{array}$ & AND & $\begin{array}{c}\text { poor OR poverty } \\
\text { OR vulnerability } \\
\text { OR vulnerable }\end{array}$ & 133 \\
& & & & OR valle & \\
\hline
\end{tabular}

Fórmula utilizada: ( TITLE-ABS-KEY ( tourism ) AND TITLE-ABS-KEY ( poor OR poverty OR vulnerability OR vulnerable ) AND TITLE-ABS-KEY ( argentina OR bolivia OR brazil OR chile OR colombia OR "Costa Rica” OR cuba OR ecuador OR “El Salvador” OR “Guayana Francesa” OR guatemala OR “Guayana” OR haiti OR mexico OR peru OR paraguay OR venezuela OR uruguay ))

En la lectura de los artículos se encontró que existen transformaciones positivas y negativas motivadas por el turismo; sin embargo, los casos presentan de forma general las implicaciones. Por ello se decidió seleccionar dos casos que cuentan con suficiente disponibilidad de información con el fin de profundizar en los procesos de transformación. Se complementó la información de los casos con datos sobre encuestas censales. Es claro que este tipo de análisis presenta limitaciones, dado que no contiene toda la información relacionada con todos los temas que involucran las publicaciones examinadas, pero se considera que permite mapear y obtener una buena comprensión y confiabilidad sobre las complejas relaciones entre las transformaciones territoriales derivadas del auge del turismo y la vulnerabilidad social.

\section{Resultados DE LA REVISIÓN}

De los 81 documentos revisados, la mayoría de las investigaciones (96\%), fueron estudios de casos en países como: México (35\%), Brasil (16\%), Perú (15\%), Colombia (9\%), Ecuador (7\%), Costa Rica (6\%), entre otros (ver gráfico 1). Los estudios revisados se publicaron entre los años 1998 y 2020; la mayoría de ellos se 
publicó en los últimos diez años y principalmente en los años 2017 y 2019 (ver gráfico 2).

Las investigaciones se desarrollaron en diferentes destinos; de playa (38\%), áreas rurales $(30 \%)$, y en parques naturales o áreas protegidas (11\%). Las publicaciones más citadas son Barkin (2003), Croes y Rivera (2017), Erskine y Meyer (2012), Hanazaki et al. (2013), Horton (2009), Leatherman y Goodman (2005), Ramos y Prideaux (2014), Stem et al. (2003) (ver gráfico 3).

Las 81 investigaciones fueron publicadas en 59 revistas adscritas a áreas como ecología y medio ambiente (36\%), turismo $(22 \%)$, ciencias sociales, historia y cultura (10\%), medicina (9\%) y geografía (7\%), entre otras. El mayor número de artículos relacionados con procesos de transformación asociados a condiciones de pobreza y vulnerabilidad social propiciados por el turismo se encontraron en las revistas Journal of Sustainable Tourism y WIT Transactions on Ecology and the Environment, con cinco artículos cada una, Worldwide Hospitality and Tourism Themes, Ocean and Coastal Management e Investigaciones Geográficas, con tres artículos cada una.

En la mayoría de las investigaciones (65\%) se utilizaron métodos cualitativos, como entrevistas, encuestas e historias de vida para los análisis realizados. Para el análisis se revisaron tanto los impactos del turismo sobre las comunidades locales y sus territorios como las propuestas que desde las experiencias analizadas buscaban disminuir los impactos negativos reportados. Es importante resaltar que el $72 \%$ de los impactos reportados fueron negativos y el $28 \%$ fueron positivos. La distribución de los principales impactos negativos se puede observar en el gráfico 4, y la distribución de los impactos positivos se presentan en el gráfico 5 .

\section{Impactos negativos del desarrollo turístico}

Los impactos negativos más frecuentes (ver gráfico 4) están relacionados con la degradación y destrucción de ecosistemas, aspecto que afecta la resiliencia y que se evidencia en la disminución de la calidad de playas, arrecifes, dunas, manglares, los procesos de deforestación, fragmentación de hábitats y disminución de poblaciones de especies locales.

Las causas más frecuentes fueron: contaminación ambiental debido al deficiente manejo de aguas residuales y desechos, sumada a la fuerte presión sobre los recursos naturales causada por el desarrollo de infraestructura de manera desordenada y de segundas residencias. Sin embargo, el impacto negativo reportado con mayor frecuencia es el aumento de la vulnerabilidad social y afectación de los medios de vida de las comunidades que habitan estos espacios y sus sistemas productivos. Estas dinámicas han sido consecuencia de la emergencia de los siguientes fenómenos: 


\section{Gráfico 1. Países origen de las investigaciones}

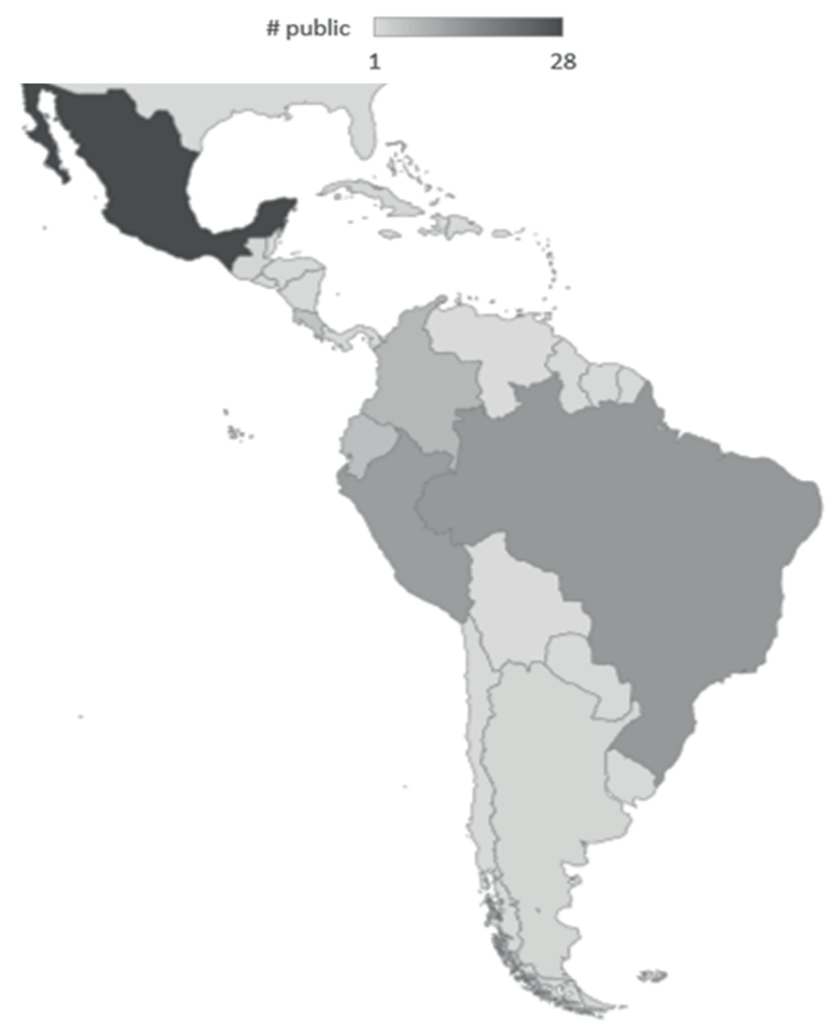

\begin{tabular}{|l|r|}
\hline Pais & \# public \\
\hline México & 28 \\
\hline Brasil & 13 \\
\hline Peru & 12 \\
\hline Colombia & 7 \\
\hline Ecuador & 6 \\
\hline Costa Rica & 5 \\
\hline Cuba & 2 \\
\hline Guatemala & 2 \\
\hline Argentina & 2 \\
\hline Bolivia & 1 \\
\hline Haiti & 1 \\
\hline Jamaica & 1 \\
\hline Venezuela & 1 \\
\hline
\end{tabular}

Gráfico 2. Publicaciones por año

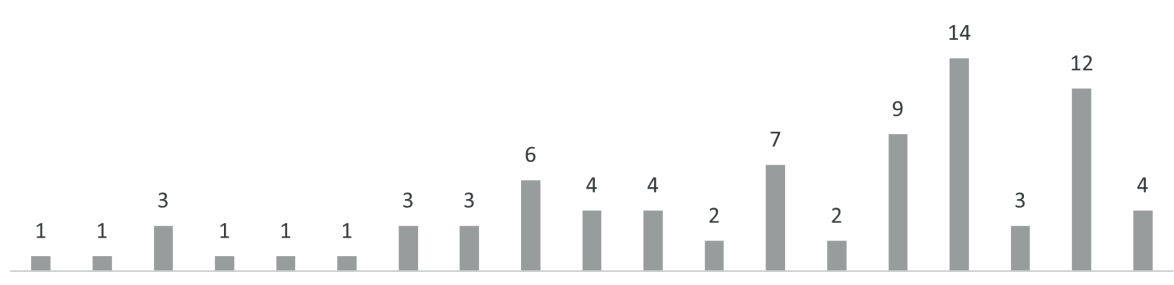

1998199920032005200620072008200920102011201220132014201520162017201820192020 
Gráfico 3. Artículos más citados

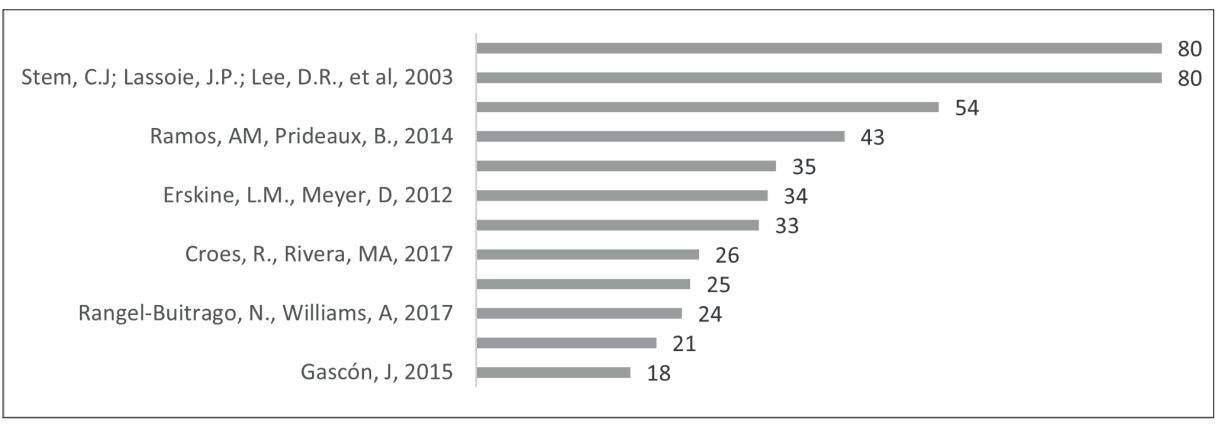

Gráfico 4. Principales impactos negativos del turismo

Destrucción y pérdida de resiliencia de ecosistemas Medios de vida vulnerables

Conflictos por el acceso y uso a recursos naturales Desigualdad en la distribución de beneficios económicos Desigualdades sociales y de poder

Baja participación local en la toma de decisiones Marginación de comunidades locales Explotación y precariedad laboral Gentrificación Construcción desordenada Baja sostenibilidad de los emprendimientos locales Cambio relación comunidad - medio ambiente Problemas de salud Pérdida de valores culturales Mercantilización de los sistemas alimentarios Mayor estratificación campesina Informalidad en la prestación de servicios Estrategias de conservación supeditadas al turismo Cambios de uso y cobertura de suelo (de vegetación a...

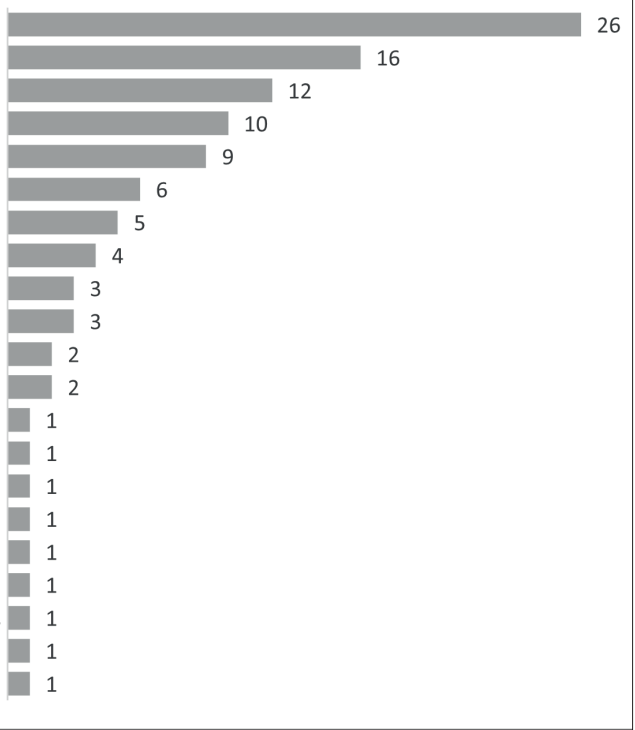

- Conflictos por el acceso y uso de los recursos en el territorio, particularmente relacionados con la propiedad e intensificación del mercado de tierras, la disponibilidad de agua y los aspectos asociados a las actividades de pesca.

- Desigualdad en la distribución de los beneficios, situación que afecta principalmente a comunidades indígenas y rurales que perciben pocos ingresos y se ven sometidas a empleo informal, informalidad, explotación y precarización del empleo, asociado con las actividades turísticas.

- Desigualdades sociales, relacionadas básicamente con los desequilibrios en las relaciones de poder, evidentes en los intereses externos o de élites que prevalecen sobre las aspiraciones de las comunidades locales. Estos desequilibrios terminan 
Gráfico 5. Principales impactos positivos del turismo

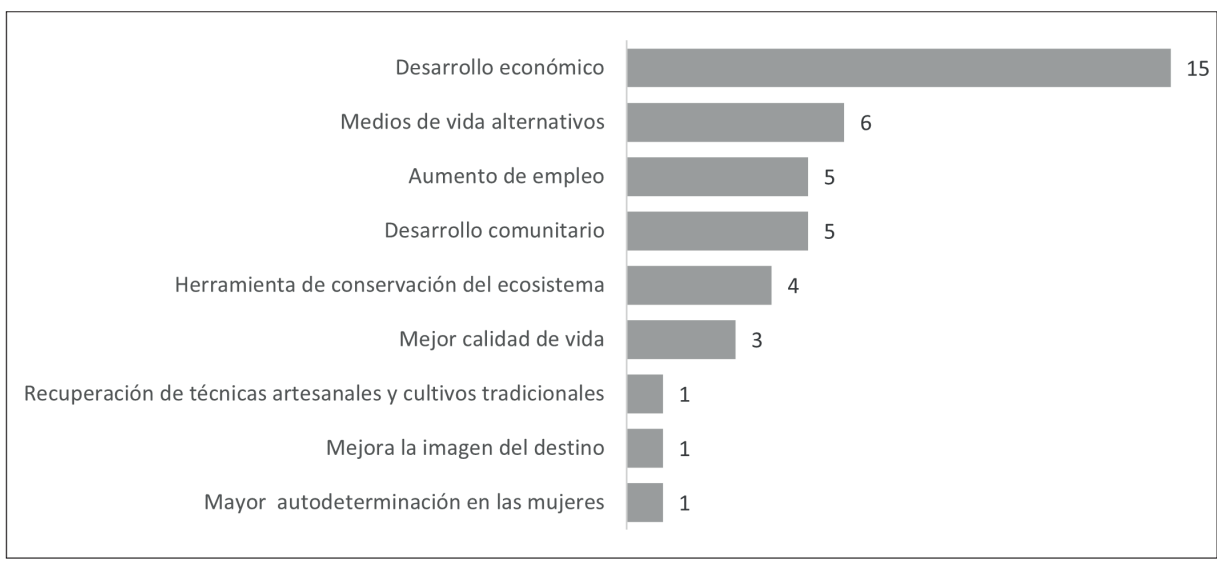

desviando los sistemas legales y las decisiones, generando baja participación local, cambios de uso del suelo para desarrollar construcciones de manera desordenada, desvío de recursos públicos, mayor estratificación y gentrificación de las comunidades rurales.

- Dependencia económica de las comunidades locales por insertarse en un sector en el que tienen bajo poder de negociación y cuyos ingresos son estacionales, lo que reduce la autonomía y el control sobre sus medios de subsistencia, generalmente imbricados con actividades de subsistencia como la pesca, la minería artesanal, la agricultura familiar y la pequeña ganadería y pastoreo.

- Agotamiento de los medios de subsistencia, generado por la degradación ambiental y la mercantilización de los sistemas alimentarios, dado que el turismo modifica la relación de la comunidad con la naturaleza y las estrategias de conservación de los recursos asociados a la subsistencia, al ser estos supeditados a los imperativos de dicha actividad.

- Mayor exposición a drogas, alcohol y turismo sexual, especialmente en niños y jóvenes.

- Presión por diversificar sus medios de subsistencia a través de diversas estrategias y proyectos que se proponen de arriba hacia abajo, desde el gobierno o las entidades de apoyo y fomento regionales.

\section{Impactos positivos del desarrollo turístico}

El impacto positivo más referenciado es el desarrollo económico (ver gráfico 5). Los estudios indican que el turismo aumenta el empleo, los ingresos de la población, y diversifica la economía local. De esta manera el turismo permite la pluriactividad y la emergencia de medios de vida alternativos, al fortalecer habilidades empresariales, 
así como capacidades individuales y comunitarias, elevar la autoestima, el respeto por la naturaleza y los valores culturales, así como motivar el avance de la educación formal, las acciones colectivas, el empoderamiento y un mayor grado de autodeterminación, especialmente en el caso de mujeres y jóvenes.

En algunas investigaciones se encontró que el turismo estimula las dinámicas desarrollo comunitario, al elevar las capacidades asociadas al capital social y humano, las redes e interconexiones locales, regionales y globales y empoderamiento local. También se identificó que el turismo resultó ser, en algunos casos, una herramienta efectiva para propiciar la conservación de los ecosistemas, la recuperación de técnicas artesanales y cultivos tradicionales, además de mejorar la imagen de los lugares de destino.

\section{Propuestas para disminuir los impactos negativos del turismo}

El mayor número de iniciativas se relaciona con el mejoramiento de los procesos de planeación turística (ver gráfico 6). Los estudios consideraron la importancia de proponer agendas ambientales y sociales con límites al crecimiento de acuerdo con la capacidad de carga de los espacios locales y sus características geográficas, socioculturales, históricas, ecológicas y económicas, así como identificar y analizar los riesgos ambientales y cambios generacionales. Para viabilizar estos procesos de planeación se requiere una amplia intervención pública y privada, vinculando a la comunidad local, sin dejar de lado las conexiones globales que existen como herramienta de innovación. Adicionalmente, se debe velar por el establecimiento de relaciones de interdependencia mutuamente beneficiosas sin caer en la dependencia, compatibilizando el empleo local, los objetivos económicos y de conservación.

Otras propuestas frecuentes están relacionadas al desarrollo turístico con una mayor participación local. Los estudios indican que, para esto, se deben generar estrategias de empoderamiento de las comunidades, la creación de redes locales de cooperación, procesos de planeación más transparentes que resalten no solo los beneficios económicos a corto plazo y el incremento de visitantes, sino también que actúen sobre los impactos negativos en el medio ambiente y los medios de vida de las comunidades locales. Además, es necesario reevaluar el papel activo de las comunidades, reconociendo que el desarrollo del turismo se genera en su propio escenario geográfico y social.

Algunos estudios proponen distribuir y reasignar de manera más equitativa los costos y beneficios provenientes del turismo regional. Para lograrlo, se plantea la necesidad de analizar las inequidades estructurales, comprender las tensiones locales, las prácticas discriminatorias y todas las barreras a la movilidad social, además de promover modelos transversales en los que se evite que toda la región sea susceptible al mismo tipo de desarrollo y actividades turísticas o que se lleven a cabo con la 
Gráfico 6. Propuesta para mejorar los impactos del turismo

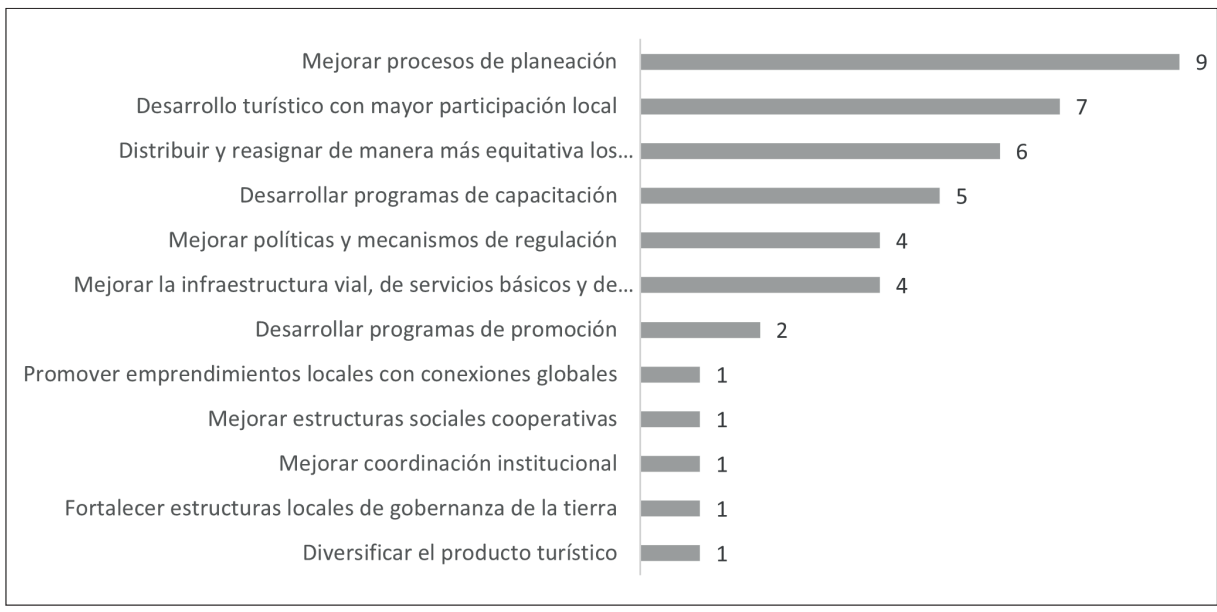

misma intensidad, para de esta manera crear mecanismos que fomenten la autodeterminación local y funcionalicen la gobernanza. Para operativizar los procesos redistributivos se requiere mejorar las políticas y mecanismos de regulación. Algunos estudios consideran que esto implica: (i) compromiso político para crear las condiciones económicas, institucionales, normativas y de generación de infraestructura que contribuyan a alcanzar este propósito sin poner en riesgo el medio ambiente y los recursos naturales de la región; (ii) considerar contradicciones globales y puntos de vista e intereses locales, combinando enfoques de desarrollo turístico basados en recursos y en la comunidad, que reconozcan las problemáticas sociales, económicas y ambientales regionales, más allá de las fronteras geográficas, abordando problemas estructurales mucho más amplios; con relación a los programas de capacitación, se propone enfatizar en las autoridades locales en mejor gestión de recursos naturales y planificación urbana en contextos turísticos, mejorar las competencias laborales y en temas relacionados con seguridad y salud, y (iii) mejorar la coordinación institucional a diversas escalas.

\section{El caso de Quintana Roo, México, un enclave que no logró los vínculos esperados y en cambio favoreció condiciones de vulnerabilidad social}

Quintana Roo forma parte de la península de Yucatán, un territorio históricamente marcado por disputas por el control de la explotación y comercialización de recursos naturales, como la madera del árbol de chicle, el hénequen (Dachary y Arnaiz, 1998) y las playas del mar Caribe. El proceso de desarrollo agrícola vino de la mano con el desarrollo de infraestructura y distritos de riego, principalmente en el sur, entre 1970 y 1975. Sin embargo, la inversión decrece hacia 1974, cuando 
la presión por las grandes inversiones federales se orienta al sector turismo. Esto obligaba al gobierno territorial a dotar de servicios mínimos a poblaciones antes olvidadas y colocadas ahora frente a grandes avances de la modernización turística. Dicho proceso se da también en el marco de una migración masiva de agricultores, principalmente de estados del bajo y norte de México a territorio quintanarroense, con la única finalidad de engrosar la base poblacional y con ello provocar que Quintana Roo abandonara su estatus de territorio federal para convertirse en la entidad número treinta y dos de México.

La estrategia de modernización iniciada en 1970 buscaba integrar el Caribe Isleño al sur de Estados Unidos, creando un enclave turístico que respondiera al proceso de declive forestal y agrícola, y sustituir a Cuba — que recién había cambiado de régimen por la revolución - como polo de destino turístico norteamericano. De esta manera, se crea el gran proyecto Cancún, impulsado por políticas de planeación nacional, basadas en Centros Integralmente Planificados (CIP), que tienen como marco de referencia los polos de desarrollo ${ }^{1}$, apoyados económicamente por el Banco Interamericano de Desarrollo y el Banco Mundial, quienes consideraban el turismo como una herramienta para promover el crecimiento y desarrollo de las naciones del llamado tercer mundo (Araújo-Santana et al., 2013; Castillo y Villar, 2014; Dachary y Arnaiz, 1998; Espinosa-Coria, 2013; Rioja et al., 2019).

De acuerdo con autores como Castillo y Villar (2014) y Espinosa-Coria (2013), dentro de los objetivos del proyecto Cancún se esperaba que el turismo permitiera generar vínculos con otros sectores en Quintana Roo y que estos vínculos impulsaran sectores como el agrícola. Sin embargo, este proceso de integración entre turismo y agricultura fracasó en esta región por diversos factores: los agricultores más productivos están geográficamente aislados de los centros de turismo, su capacidad productora es casi nula respecto de otras regiones agrícolas, hay poco poder de negociación debido a diferencias étnicas y de clase con los compradores en la industria del turismo, la calidad de los insumos no cumple los estándares exigidos por la industria, a los productores les resulta difícil cumplir volúmenes constantes y existen altos niveles de intermediación (Barrera et al., 2016; Cuevas y Cavazos, 2019).

Es evidente que el proyecto logró crear puestos de trabajo, generar divisas y propició el crecimiento de una urbe en un punto prácticamente deshabitado del territorio mexicano. Sin embargo, no se alcanzó la integración económica de la región, porque Cancún tiene poca relación productiva con el área circundante y la base material del estado descansa excesivamente en el sector turismo, existe alta informalidad, estacionalidad y precariedad del empleo que vulnera la vida de los

\footnotetext{
Término utilizado por Perroux en la década de 1950 para explicar cómo se produce el crecimiento económico y las razones por las que todo proceso de crecimiento tiende a ser desequilibrado.
} 
trabajadores del ramo turístico de la región, además de diversos problemas asociados con la violencia; pobreza y segregación (Ay et al., 2019; Barrera-Rojas, 2020; Espinosa-Coria, 2013; Fragoso, 2016; Minerva, 2017; Moreno y Hernández, 2019; Oehmichen, 2010).

En la metodología mexicana, la pobreza tiene una relación más marcada con el ingreso y las condiciones de vida que guardan los hogares (CONEVAL, 2010). En este sentido, Barrera-Rojas (2020) analiza la evolución de la pobreza y la vulnerabilidad en Quintana Roo en el periodo 2010-2016. En este análisis de Benito Juárez -el municipio donde está Cancún - tanto la pobreza como la pobreza moderada reportaron incrementos en sus cifras absolutas; es decir, los pobres pasaron de 180048 a 219949 personas, los pobres moderados pasaron de 155556 a 199173 personas, mientras que los vulnerables por carencias —es decir, la población que padece tres o más dimensiones de pobreza - aumentaron de 258291 a 284301 personas, y los vulnerables por ingresos —es decir, la población que tiene menos de tres carencias de dimensiones de pobreza, pero cuyos ingresos resultan insuficientes para adquirir la canasta básica — pasaron de 35870 a 56553.

Para autores como Ay et al. (2019), estos elementos se identifican como el agotamiento de la urbe. Como Cancún fue intenso e intensivo en mano de obra - especialmente rural — que se ocupó en la construcción de hoteles y de la propia ciudad, se generó la idea de "un Cancún lleno de oportunidades de trabajo» (Minerva, 2017), lo que propició una migración masiva tanto de la población maya como de la proveniente de otros estados de la república y extranjeros, principalmente centroamericanos. Esto generó un crecimiento desordenado en la periferia y se dieron brotes de asentamientos irregulares, con distorsión de precios de la vivienda y del suelo.

Lo anterior también ocurrió en la Riviera Maya, Playa del Carmen y Cozumel, que registraron incrementos en las tasas de carencia de vivienda de calidad y proliferación de asentamientos irregulares. De hecho, en el mapa 1 se observa que la llamada zona hotelera del Kukulkan es la región que registra hogares con menores índices de pobreza (Barrera-Rojas, 2020). La zona centro de Cancún —-donde se aloja la mayor parte de la infraestructura de gobierno, bancaria, de hoteles no de lujo, y servicios comerciales - es la que sigue en orden de menores condiciones de pobreza. A partir de esa zona se observa el efecto centro-periferia. Las zonas más alejadas del centro de Cancún son las que presentan mayor concentración de hogares en condiciones de pobreza, entre $70 \%$ y $100 \%$.

Así, Cancún se transformó en un polo de desarrollo que sin duda generó crecimiento económico, empleos, atracción de divisas, flujo de capitales y un importante posicionamiento internacional del Caribe mexicano; sin embargo, también es evidente que cambió la distribución espacial de la población, distorsionó los 
Mapa 1. Pobreza en Cancún por AGEB, 2015

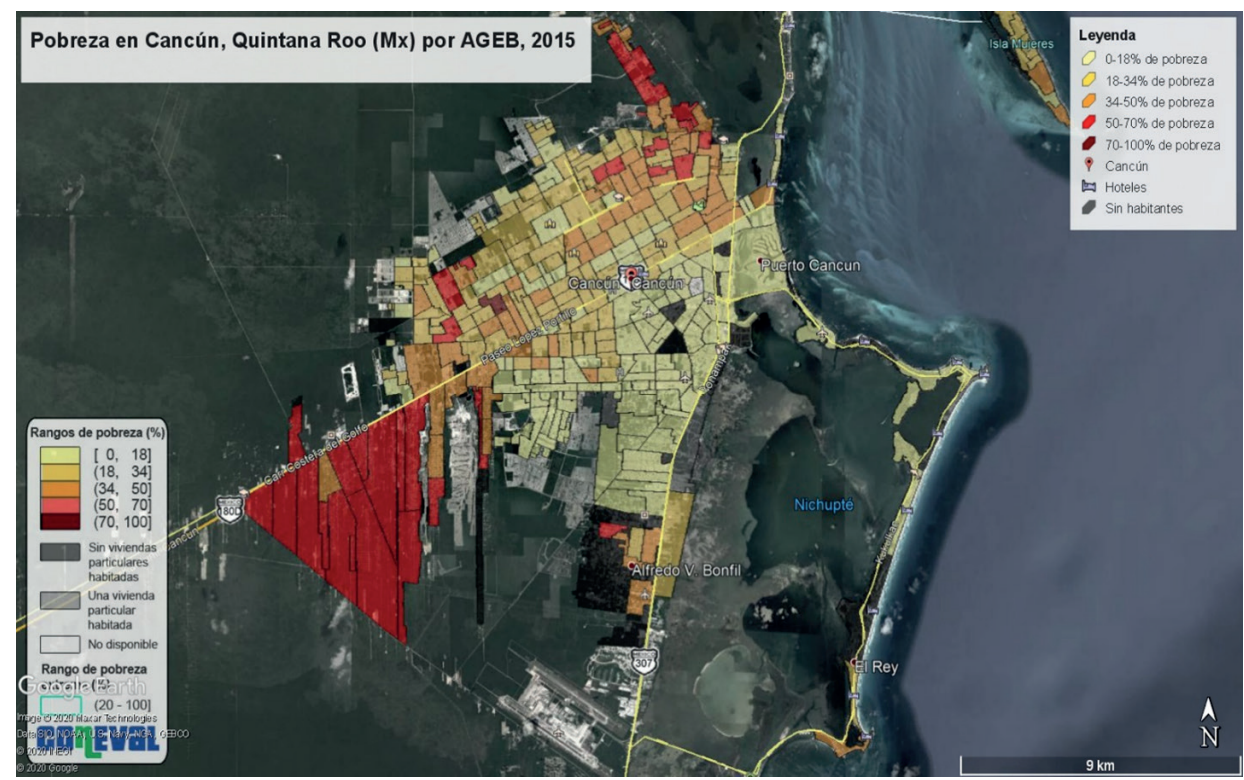

Fuente: (CONEVAL, 2017)

precios del suelo, cambió los ejes de acumulación que pasan a la industria turística y la construcción, generó una profunda polarización económica-política y social y aumentó la vulnerabilidad social de las comunidades locales al tratar inútilmente de vincular la frágil economía estacional con el flujo de capital global proveniente del turismo que exige oferta de todo tipo de bienes y servicios en Cancún.

\section{El caso del Distrito Turístico y Cultural de Cartagena de Indias en Colombia, vulnerabilidad social impulsadas por los cambios en el uso del suelo por cuenta del turismo}

El turismo en Cartagena inicia hacia 1920, al convertirse en puerto de los circuitos de la industria de cruceros de Estados Unidos. En la década de 1930 se dio impulso al turismo cultural a través de festivales y en la de 1940 fue nombrado primer destino turístico de Colombia. Alrededor de 1950 se construyó la Troncal de Occidente mejorando la conexión con el centro del país. En esa época, el atractivo principal era el sol y playa, que motivó en la siguiente década la construcción de edificios e infraestructura hotelera de alto nivel. Para los años setenta del siglo $\mathrm{XX}$, la élite nacional se interesó en el centro histórico, comprando y restaurando casas, lo cual genero el traslado de la población local, como el barrio Chambacú. En la década de 1980 fue nombrada Patrimonio Histórico de la Humanidad por 
Unesco, lo que dio valor al centro histórico y la ciudad antigua. En la década de 1990 se construyeron grandes complejos turísticos y hoteles y se expandió hacia las islas, y al empezar el siglo XXI, la tasa de crecimiento de la construcción superaba el promedio nacional y se impulsó la actividad portuaria y el turismo de cruceros (Aguilera y Meisel, 2009; Ávila, 2008; Bassols, 2018).

$\mathrm{El}$ anterior panorama ha generado diversos ajustes desde la planeación. El Plan de Ordenamiento Territorial (POT) ${ }^{2}$ de 2001 — vigente hasta la fecha— pone énfasis en la conservación del patrimonio natural, histórico y cultural, para hacer de Cartagena un lugar que genere desarrollo regional y que sea reconocido internacionalmente como centro turístico, portuario, industrial y de negocios. Entre otras se definen: (i) zonas de alto valor turístico, como las islas de Barú, Tierrabomba, la Boquilla y el Parque Islas del Rosario; (ii) áreas de protección y conservación de recursos naturales y paisajísticos ${ }^{3}$, y (iii) zonas de conservación histórica, ambiental y urbanística: Centro, San Diego y Getsemaní (Alcaldía de Cartagena, 2001). Las expectativas del plan incluían contener el deterioro, prevenir riesgos, proteger el patrimonio, mejorar el hábitat de la población marginal, asegurar disponibilidad de agua potable, ordenar y adecuar las inmediaciones de los atractivos turísticos, entre otros. Sin embargo, la ejecución de estas estrategias ha tenido serios inconvenientes debido a la falta de gobernabilidad, desarticulación institucional y corrupción, evidente en la designación entre 2001 y 2018 de trece alcaldes, que en un proceso normal debieron ser seis.

Durante este periodo, los planes de desarrollo de la ciudad (2001-2003, 20042006, 2008-2011, 2012-2015, 2016-2019) coinciden con el propósito de ver a Cartagena como una ciudad competitiva, priorizando el turismo como una estrategia de desarrollo. En los primeros periodos, se fortaleció la oferta de servicios, formalización, emprendimiento, creación de política pública, normas y estímulos a la inversión. Luego, fue central la conectividad aérea, el desarrollo de infraestructura vial y marítima —así como de equipamientos turísticos—, y después, la promoción focalizada en playas, casco histórico, centro náutico e integración a redes globales de turismo. Los planes más recientes impulsan la sostenibilidad a través del diseño y ejecución de planes de manejo, recuperación y conservación de zonas turísticas con ecosistemas sensibles, como el Cerro de la Popa, las islas, playas, ciénagas y

\footnotetext{
2 Los POT en Colombia son el conjunto de directrices, políticas, estrategias, metas, programas, actuaciones y normas que se adoptan para orientar y administrar el desarrollo físico del territorio y la utilización del suelo.

3 Parque Nacional Natural Corales del Rosario y San Bernardo, Parque Forestal y Zoológico Cacique Dulio, Cerro de la Popa, Lomas de Albornoz y Cospique, Parque de Henequén, Parque Distrital Ciénaga de la Virgen, Bahía de Cartagena, entre otros.
} 
manglares y el impulso a nuevas formas de turismo, como el ecoturismo, el turismo rural y la medición de impactos.

Estos procesos de planeación, más la tendencia de crecimiento del turismo global, han llevado a Cartagena a convertirse en uno de los principales destinos turísticos de Colombia. En 2018, a la ciudad llegaron más de tres millones de turistas, se generó el 48\% de empleo, el turismo aportó el 10\% al PIB departamental, se revalorizaron diferentes zonas de la ciudad y se incrementó la actividad comercial y empresarial, así como la inversión extranjera ${ }^{4}$. Sin embargo, la sostenibilidad de la ciudad como destino turístico presenta problemas por el aumento del nivel del mar, que ha puesto en riesgo de inundaciones al 25\% de la población y sus propiedades, el incremento de asentamientos ilegales y de barrios pobres, la amenaza de erosión y pérdida de valor paisajístico del centro colonial histórico (UNESCO, n.d.), un relleno sanitario con poca vida útil pero con un incremento sostenido en la producción de residuos sólidos (Plan Desarrollo, 2017), así como por la prevalencia de VIH más alta del país (Djellouli y Quevedo-Gómez, 2015). Además, su sistema de fortificaciones militares —el más extenso y uno de los más completos de Sudamérica (ICOMOS, 2017) - está deteriorado, con secciones dañadas y riesgo de colapso, debido a factores ambientales y antropogénicos como la polución provocada por la cercanía del tráfico. Asimismo, el desarrollo urbanístico superaba el promedio nacional y se impulsa la actividad portuaria y el turismo de cruceros (Aguilera y Meisel, 2009; Ávila, 2008; Bassols, 2018; Mestre y Castillo, 2017; Saba et al., 2019).

Algunas investigaciones consideran que parte de estas causas están asociadas con deficientes procesos de planeación y gestión en la ciudad, que no han tenido en cuenta la evolución urbanística y medioambiental, y con intereses de grandes inmobiliarias, inversionistas del turismo y empresas constructoras, que buscan capturar la plusvalía a través de potenciar comercial, turística y residencialmente algunos lugares. Ello genera un desordenado e irregular proceso de construcción de edificios, hoteles, viviendas, zonas comerciales, y estructuras costeras para servicios náuticos y navales (Bassols, 2018; Horta, 2016; Mestre y Castillo, 2017; Rius-Ulldemolins y Jiménez, 2016).

Estos procesos de expansión e intensificación no solo ponen en riesgo la apariencia del destino, sino que estimulan actividades extractivas para proveer a la construcción y generan una inadecuada disposición de residuos sólidos y líquidos que transforman coberturas del suelo y aumentan su degradación. Lo anterior se vuelve más evidente en las zonas que fueron priorizadas en Cartagena como de alto valor turístico y que mencionamos a continuación.

4 Datos de Corpoturismo, SITCAR y Cámara de Comercio de Cartagena. 
Las playas de Barú, Boquilla, Tierra Bomba y los archipiélagos del Rosario y San Bernardo han sido urbanizados, lo que ha generado nuevas formas de ordenar y usar el suelo de rural a suburbano y ha aumentado la especulación y apropiación de la tierra para construir hoteles y segundas residencias. Este cambio en usos y coberturas del suelo ha generado impactos negativos sobre los servicios ecosistémicos, especialmente de aprovisionamiento, incrementándose los conflictos por el acceso y control del uso del suelo, agua potable, playa y recursos marinos. Además, ha modificado las formas de vida social y económica de los pobladores locales, al cambiar o extinguir las actividades productivas tradicionales y culturales, pasando de pescadores y agricultores a prestadores de servicios turísticos. Estos cambios en los modos de subsistencia han aumentado la vulnerabilidad de los habitantes de las zonas rurales, lo que se hace evidente en las cifras de Necesidades Básicas Insatisfechas (NBI) que para 2018, según la Secretaría de Planeación de la ciudad, estaban en 96,6\%, y las de Miseria en 55,1\% (Berdugo et al., 2004; Buitrago, 2017; Horta, 2016; Marín, 2016; Peñas y Trocha, 2018; Pineda et al., 2006; Posada y Henao, 2008; Sánchez 2013; Siegert, 2006).

En los barrios San Diego y Getsemaní, el desarrollo turístico fue el principal motor de cambios en el uso del suelo (Deavila, 2015). Estos barrios fueron declarados áreas de conservación por su alto valor arquitectónico, hoy de gran interés para el turismo residencial y de agentes privados nacionales y extranjeros que compran y valorizan el espacio, impulsando la restructuración funcional de los barrios a procesos de gentrificación. Estas áreas se han ido adaptando a los requerimientos del turista, un barrio despejado, «limpio», confortable, silencioso, para observar el patrimonio arquitectónico, pero distante del contexto social. Este proceso no cambia las coberturas del suelo, sino que intensifica su uso residencial y comercial, lo cual conlleva a un fuerte impacto en el tejido social debido al incremento del impuesto predial, nivel de vida, especulación de la tierra y altos precios de los inmuebles, así como de los costos de servicios públicos. Esto conlleva a la sustitución y desalojo de los locales, impulsándolos a ocupar zonas vulnerables en un destino turístico que puede perder capacidad para sostenerse en el tiempo (Bassols, 2018; Castañeda, 2017; Deavila, 2015; Garcés, 2015; Mestre y Castillo, 2017; Pérez, 2013; Piñeros, 2017; Rius-Ulldemolins y Jiménez, 2016; Saba, et al., 2019).

\section{Conclusiones}

Gran parte de los estudios revisados muestran que el hecho de no tomar en cuenta las particularidades del territorio en el desarrollo de actividades económicas como el turismo genera diversos impactos — no siempre positivos—, entre ellos, la dificultad de acceso de la población a recursos como suelo, agua y energía por el aumento de 
su consumo, la destrucción de paisajes, el cambio en los usos del suelo de producción agrícola a atractivo turístico, el aumento de la producción de residuos, la alteración de ecosistemas, la inducción de flujos de población hacia las zonas de concentración turística, la pérdida de valores tradicionales y de diversidad cultural, el aumento de la prostitución (turismo sexual), el tráfico de drogas y las mafias, el incremento de precios que afecta a la población local, la expansión de la frontera turística y urbana en las zonas rurales, el cambio de concepción de la propiedad de la tierra de colectiva a privada, el cambio en los usos del agua de insumo para la actividad agrícola a atractivo turístico, el cambio de valor de la tierra de productividad agrícola a atractivo paisajístico, la migración, puerta de entrada de productos foráneos que generando competencia desigual con los mercados locales, entre otras. Estos impactos aumentan las condiciones de vulnerabilidad social de los medios de vida de las comunidades residentes, particularmente en áreas rurales.

Estas condiciones de vulnerabilidad generan círculos de pobreza e inequidad, características recurrentes en los países latinoamericanos. Por ello, el papel del Estado y el funcionamiento de sus estructuras de acceso, regulación y control de bienes y servicios para la provisión de bienestar al grueso de la población son fundamentales.

Es claro que el Estado y sus instituciones deben proveer un contexto adecuado para el desarrollo de la actividad turística, tanto desde la perspectiva de la planeación, la regulación y protección de los atractivos turísticos, como de la provisión de un contexto favorable para una adecuada participación del capital y la población local en la actividad turística, más allá de la funcionalización de grandes enclaves de servicios turísticos gerenciados por el gran capital, donde las consideraciones de protección tanto de los recursos naturales como de los derechos laborales es precaria, y donde la competitividad y rentabilidad se centran en la sobreexplotación de los recursos naturales y humanos locales.

Así, además de la provisión de incentivos a la inversión extranjera y de infraestructura básica de saneamiento, servicios públicos, comunicaciones y transporte en los polos de desarrollo turístico, el Estado debe propender a mejorar las condiciones de acceso a salud, educación, crédito y garantías civiles mínimas para que la población local pueda participar efectivamente y beneficiarse del auge de la actividad, se proteja y regule el acceso a atractivos turísticos con características de recursos de uso común, y se planifique y democratice su uso sostenible. 


\section{REFERENCIAS}

Adger, W. (2006). Vulnerability. Global Environmental Change, 16(3), 268-281. https://doi. org/10.1016/J.GLOENVCHA.2006.02.006

Aguilera, M. y Meisel, A. (2009). Tres siglos de historia demográfica de Cartagena de Indias (colección de Economía Regional). Recuperado de https://www.banrep.gov.co/sites/ default/files/publicaciones/archivos/lbr_3_siglos_histo_demo_cartag_0.pdf

Alcaldía de Cartagena (2001). Plan de Ordenamiento Territorial del Distrito Turístico y Cultural de Cartagena de Indias.

Amelung, B., Student, J., Nicholls, S., Lamers, M., Baggio, R., Boavida-Portugal, I., Johnson, P., de Jong, E., Hofstede, G., Pons, M., Steiger, R. y Balbi, S. (2016). The value of agent-based modelling for assessing tourism-environment interactions in the Anthropocene. Current Opinion in Environmental Sustainability, 23, 46-53. https://doi.org/10.1016/j.cosust.2016.11.015

Araújo-Santana, M., Parra-Vázquez, M., Salvatierra-Izaba, E., Arce-Ibarra, A. y Montagnini, F. (2013). Políticas turísticas, actores sociales y ecoturismo en la península de Yucatán. Economía Sociedad y Territorio, 3(43), 641-674. https://doi.org/10.22136/ est00201342

Ashley, C. y Goodwin, H. (2007). «Turismo pro-pobre». ¿Qué ha ido bien y qué ha ido mal? En Opinion. Overseas Deelomment Institute (p. 2). Recuperado de https://cdn. odi.org/media/documents/142.pdf

Ávila, F. (2008). La representación de Cartagena de Indias en el discurso turístico. Cuaderno de Trabajo, 2, Issue 2. Recuperado de https://www.nacionmulticultural.unam.mx/ mezinal/docs/6185.pdf

Ay, F., Barrera, M. y Torres, R. (2019). ¿Puede basarse el desarrollo regional en turismo?: Cancún como caso de estudio. AvaCient, 7(2), 67-75. Recuperado de http://www. itchetumal.edu.mx/avacient/index.php/revista/issue/view/12/3

Barkin, D. (2003). Alleviating poverty through ecotourism: Promises and reality in the Monarch butterfly reserve of Mexico. Environment, Development and Sustainability, 5(3-4), 371-382. https://doi.org/10.1023/A:1025725012903

Barrera, M., Romero, R. y Chargoy, P. (2016). Aplicación de Técnicas de Análisis Regional para Quintana Roo, México utilizando el PIB municipal (2003-2008). Revista de Estudios Interculturales, 1(3), 54-73. Recuperado de http://www.estudiosinterculturales.com/articulos/vol-3/4_tecnicas_regionales_Miguel_Barrera_REI_No_3.pdf

Barrera-Rojas, M. (2020). ¿Disminución de la pobreza en México? Estudio de caso para Quintana Roo 2010-2016. Visión de Futuro, 24(1). Recuperado de https://www. redalyc.org/articulo.oa?id=357961649008

Bassols, N. (2018). Evolving Iconization and Destination Building: The Example of Cartagena, Colombia. Tourism Planning \& Development, 1-19. https://doi.org/10.1080/ 21568316.2018.1501730

Berdugo, M., Betancourt, A., Maldonado, A. y Garzón, J. (2004). Evaluación y dinámica de uso del recurso hídrico en el corregimiento de Barú (Cartagena, Bolívar, Colombia). 
Acta Biológica Colombiana, 9(1), 23. Recuperado de https://revistas.unal.edu.co/ index.php/actabiol/article/viewFile/27075/27349

Blaikie, P., Cannon, T., Davis, I. y Wisner, B. (1996). Vulnerabilidad. El entorno social, político y económico de los desastres. En Primera Edición: Julio de 1996. Recuperado de http://www.desenredando.org/public/libros/1996/vesped/vesped-todo_sep-092002.pdf

Boullón, R. (2006). Planificación del espacio turístico (Trillas). Recuperado de https://www. entornoturistico.com/wp-content/uploads/2017/02/Planificación-del-espacioturístico-de-Roberto-C.-Boullon-PDF.pdf

Buades, J., Cañada, E. y Gascón, J. (2012). El turismo en el inicio del milenio: una lectura a tres voces (Foro de Tu). Recuperado de http://www.albasud.org/publ/docs/51.pdf

Buckley, R. (2011). Tourism and Environment. Annual Review of Environment and Resources, 36(1), 397-416. https://doi.org/10.1146/annurev-environ-041210-132637

Buitrago, A. (2017). La historia de Barú, Cartagena. Cuadernos del Caribe, 23, 34-59. Recuperado de https://revistas.unal.edu.co/index.php/ccaribe/article/view/67606

Busso, G. (2001). Vulnerabilidad social: nociones e implicancias de políticas para Latinoamérica a inicios del siglo XXI. En C. Naciones Unidas, CEPAL (ed.), Seminario internacional Las diferentes expresiones de la vulnerabilidad social en América Latina y el Caribe (pp. 1-39). CEPAL. Recuperado de https:/www.cepal.org/publicaciones/ $\mathrm{xml} / 3 / 8283 / \mathrm{GBusso} . \mathrm{pdf}$

Cańada, E. y Gascón, J. (2007). Turismo y desarrollo. Herramientas para una mirada crítica (Enlace). Fundación Luciérnaga - Acción por un Turismo Responsable. Recuperado de http://www.albasud.org/downloads/142.pdf

Castañeda, L. (2017). Getsemani: Turismo, desplazamiento y otras facetas de la gentrificación. Recuperado de http://repository.usta.edu.co/handle/11634/9267

Castillo, O. y Villar, A. (2014). El Estado y la política de los polos turísticos de desarrollo: el caso de Cancún, México. Revista de Urbanismo, 31, 18-36. https://doi. org/10.5354/0717-5051.2014.33059

Centre for Evidence-Based Conservation. (2010). Guidelines for Systematic Review in Environmental Management. Version 4.0. Environmental Evidence. Recuperado de https://environmentalevidence.org/wp-content/uploads/2014/06/Review-guidelines-version-4.2-final.pdf

Chambers, R. y Conway, G. (1991). Sustainable rural livelihoods: practical concepts for the 21 st century. En Ids Discussion Paper (Vol. 296). Recuperado de https://opendocs. ids.ac.uk/opendocs/bitstream/handle/20.500.12413/775/Dp296.pdf?sequence=1

Climent, I. (2001). Tercer mundo, desarrollo, desastres y tecnología. Una mirada desde la geografía. Serie Geográfica, 10, 11-26. Recuperado de https:/ebuah.uah.es/dspace/ bitstream/handle/10017/1157/OK-01-Revista-Articulo-Ignacio\%2520Alonso\%2520$11 \% 2520 \mathrm{a} \% 252026 \% 5 \mathrm{~B} 1 \% 5 \mathrm{D}$.pdf?sequence=1\&isAllowed $=\mathrm{y}$

Comerio, N. y Strozzi, F. (2019). Tourism and its economic impact: A literature review using bibliometric tools. Tourism Economics, 25(1), 109-131. https://doi. org/10.1177/1354816618793762 
CEPAL (2015). Panorama social de América Latina. Recuperado de https://repositorio. cepal.org/bitstream/handle/11362/39965/S1600175_es.pdf

CONEVAL (2010). Lineamientos y criterios generales para la definición, identificación y medición de la pobreza (Diario Oficial de La Federación). Recuperado de https:// www.coneval.org.mx/Normateca/Documents/Lineamientos-DOF-180809.pdf

CONEVAL (2017). Pobreza urbana en México, 2015. Recuperado de https://www.coneval. org.mx/Medicion/Paginas/POBREZA-URBANA-EN-MEXICO-2015.aspx

Cordero, A. (2006). Nuevos ejes de acumulación y naturaleza. El caso del turismo (CLACSO). Recuperado de http://biblioteca.clacso.edu.ar/clacso/becas/20110205114102/cordero.pdf

Croes, R. y Rivera, M. (2017). Tourism's potential to benefit the poor: A social accounting matrix model applied to Ecuador. Tourism Economics, 23(1), 29-48. https://doi. org/10.5367/te.2015.0495

Cuevas, V. y Cavazos, J. (2019). Uso de plantas aromáticas en el sector turismo en Tulum, Quintana Roo, México para la identificación de nuevos nichos productivos en la región. El Periplo Sustentable, 37, 205-221. https://doi.org/10.36677/elperiplo. v0i37.9214

Dachary, A. y Arnaiz, S. (1998). El Caribe mexicano, una frontera olvidada. Universidad de Quintana Roo. Recuperado de http://smjegupr.net/wp-content/uploads/2013/01/ El-Caribe-Mexicano-una-frontera-olvidada-Alfredo-Cesar-Dachary1.pdf

Deavila, O. (2015). Los desterrados del paraíso: turismo, desarrollo y patrimonialización en Cartagena a mediados del siglo XX. En A. Abello Vives y F. Flórez Bolívar (eds.), Los desterrados del paraiso. Raza, pobreza y cultura en Cartagena de Indias (pp. 123146). Maremagnum.

Djellouli, N. y Quevedo-Gómez, M. (2015). Challenges to successful implementation of HIV and AIDS-related health policies in Cartagena, Colombia. Social Science and Medicine, 133, 36-44. https://doi.org/10.1016/j.socscimed.2015.03.048

Erskine, L. y Meyer, D. (2012). Influenced and influential: The role of tour operators and development organisations in tourism and poverty reduction in Ecuador. Journal of Sustainable Tourism, 20(3), 339-357. https://doi.org/10.1080/09669582.2011. 630470

Espinosa-Coria, H. (2013). El origen del proyecto turístico Cancún, México. Una valoración de sus objetivos iniciales a 42 años de su nacimiento. LiminaR. Estudios Sociales y Humanísticos, 11(1), 154-167. Recuperado de http://www.scielo.org.mx/scielo. php?pid=S1665-80272013000100011\&script=sci_arttext\&tlng=pt

FAO (2017). El estado mundial de la agricultura y la alimentación. Recuperado de http:// www.fao.org/3/a-I7658s.pdf

Foschiatti, A. (2009). Vulnerabilidad global: cuestiones de terminología. In Aportes conceptuales y empíricos de la vulnerabilidad global (pp. 1-40). Universidad Nacional del Nordeste. http://hum.unne.edu.ar/publicaciones/instGeo/digitales/vulnerabilidades/archivos/cap1.pdf 
Fragoso, P. (2016). Más allá del paraíso caribeño: malestares sociales y violencias en la vida de las juventudes en Cancún. Pueblos y Fronteras, 11(22), 68-99. Recuperado de http://www.scielo.org.mx/scielo.php?script=sci_arttext\&p $\mathrm{id}=$ S1870-41152016000200068

Gallego, I. (2015). Vulnerabilidad de los destinos turisticos Propuesta de un Sistema de indicadores para su gestión [Universidad de Málaga]. Recuperado de https://riuma.uma.es/ xmlui/handle/10630/10344

Garcés, D. (2015). ¡La historia nuestra, Caballero! Turismo, invisibilidad y gentrificación. Cuadernos de Música, Artes Visuales y Artes Escénicas, 10(2), 57-70. https://doi. org/10.11144/Javeriana.mavae10-2.hnct

Gascón, J. y Milano, C. (2017). El turismo en el mundo rural. ¿Ruina o consolidación de las sociedades campesinas e indígenas? Turismo y Patrimonio Cultural, 209. Recuperado de http://www.pasosonline.org/Publicados/pasosoedita/PSEdita18.pdf

Gascón, J. y Ojeda, D. (2014). Turistas y campesinado: El turismo como vector de cambio de las economías campesinas en la era de la globalización. Madrid; El Sauzal (Tenerife): Foro de Turismo Responsable. Recuperado de http://www.pasosonline.org/ Publicados/pasosoedita/PSEdita12.pdf

Gössling, S. (2002). Global environmental consequences of tourism. Global Environmental Change, 12(4), 283-302. https://doi.org/10.1016/S0959-3780(02)00044-4

Gössling, S. y Peeters, P. (2015). Assessing tourism's global environmental impact 19002050. Journal of Sustainable Tourism, 23(5), 639-659. https://doi.org/10.1080/096 69582.2015.1008500

Hanazaki, N., Berkes, F., Seixas, C. y Peroni, N. (2013). Livelihood Diversity, Food Security and Resilience among the Caiçara of Coastal Brazil. Human Ecology, 41(1), 153-164. https://doi.org/10.1007/s10745-012-9553-9

Herrera, J., Herrera, K. y Herrera, Y. (2017). Eufemismos bioéticos de la pobreza: clase vulnerable colombiana entre las estadísticas y la realidad. Revista Latinoamericana de Bioética, 17(32), 80-101. https://doi.org/10.18359/rlbi.2203

Horta, L. (2016). Desarrollo y conflicto: conflictos asociados al desarrollo; turismo e infraestructura, en tres corregimientos de Cartagena de Indias 1990-2015. Universidad Javeriana. Recuperado de http://repositorioslatinoamericanos.uchile.cl/handle/2250/3075768

Horton, L. (2009). Buying up nature: Economic and social impacts of Costa Rica's ecotourism boom. Latin American Perspectives, 36(3), 93-107. https://doi. org/10.1177/0094582X09334299

ICOMOS (2017). Informe sobre la Misión de Asesoramiento de ICOMOS a «Puerto, Fortalezas y Grupo de Monumentos, Cartagena» (Colombia). Recuperado de https:// www.mincultura.gov.co/prensa/noticias/SiteAssets/Paginas/Unesco-se-pronunciafrente-al-estado-de-las-F-ortificaciones-de-Cartagena-de-Indias/Traduccion $\% 20$ al\%20Espa\%C3\%B1 ol\%20Informe\%20sobre\%20la\%20Misi\%C3\%B3n\%20 de\%20Asesoramiento\%20de\%20Icomos\%20Unesco.pdf 
Kaztman, R. y Filgueira, C. (1999). Marco conceptual sobre activos, vulnerabilidad y estructura de oportunidades (p. 25). CEPAL. Recuperado de https://repositorio.cepal.org/ bitstream/handle/11362/28663/lcmvd176rev1_es.pdf?sequence=1 \&isAllowed=y

Lampis, A. (2009). Vulnerability and Poverty: An assets, resources and capabilities impact study of low-income groups in Bogota (Issue 1) [London School of Economics and Political Science]. Recuperado de http://etheses.lse.ac.uk/2743/

Leatherman, T. y Goodman, A. (2005). Coca-colonization of diets in the Yucatan. Social Science and Medicine, 61(4 SPEC. IS), 833-846. https://doi.org/10.1016/j. socscimed.2004.08.047

Maguigad, V. (2013). Tourism planning in archipelagic Philippines: A case review. Tourism Management Perspectives, 7, 25-33. https://doi.org/10.1016/j.tmp.2013.03.003

Marín, A. (2016). Historia de una expulsión: Macondo y la materialización de la exclusión. Maguaré, 60(1), 247-278. Recuperado de https://revistas.unal.edu.co/index.php/ maguare/article/view/62904

Mestre, M. y Castillo, A. (2017). Retos urbanos y medioambientales para una mejor gestión del patrimonio cultural en cuatro ciudades del Caribe: La Habana, San Juan Viejo, Santo Domingo y Cartagena de Indias. Arquitectura, Ciudad y Entorno, 11(33). 87-116. https://doi.org/10.5821/ace.11.33.4784

Minerva, S. (2017). Migración y violencia en Cancún estudio de dos asentamientos irregulares. Revista NuestrAmérica, 5(10), 68-89. Recuperado de https://dialnet.unirioja. es/servlet/articulo?codigo $=6196209$

Moreno, F. y Hernández, C. (2019). La segregación socio-espacial en dos ciudades turísticas costeras: Acapulco y Cancún. Revista Nodo, 13(25), 8-24. Recuperado de http:// revistas.uan.edu.co/index.php/nodo/article/view/157

Moser, C. (1998). The asset vulnerability framework: Reassessing urban poverty reduction strategies. World Development, 26(1), 1-19. https://doi.org/10.1016/ S0305-750X(97)10015-8.

Naciones Unidas. (2017). Informe de los objetivos de Desarrollo Sostenible 2017. Recuperado de https://unstats.un.org/sdgs/files/report/2017/TheSustainableDevelopmentGoalsReport2017_Spanish.pdf

Naciones Unidas y OMT (2010). Recomendaciones internacionales para estadisticas de turismo (No 83; Estudios de Métodos). Recuperado de https://unstats.un.org/unsd/publication/Seriesm/SeriesM_83rev1s.pdf

Oehmichen, C. (2010). Cancún: la polarización social como paradigma en un México Resort. Alteridades, 20(40), 23-34. Recuperado de http://www.scielo.org.mx/scielo. php?script=sci_arttext $\&$ pid=S0188-70172010000200003

OMT (2001). Apuntes de Metodología de la Investigación en Turismo (p. 349). Recuperado de https://www.e-unwto.org/doi/pdf/10.18111/9789284404889

Peñas, M. y Trocha, D. (2018). Informe de Calidad de vida 2018 - Cartagena cómo vamos. Recuperado de http:/www.cartagenacomovamos.org/nuevo/wp-content/ uploads/2019/09/Informe_de_Calidad_de_Vida-2018_Cartagena_Cómo_Vamos. pdf 
Pérez, A. (2013). Ese barrio vale plata... ¡pero no está a la venta! Imaginarios urbanos en el barrio Getsemaní en Cartagena de Indias. Tabula Rasa, 18, 257-274. Recuperado de https:/www.redalyc.org/pdf/396/39629177011.pdf

Piketty, T. (2019). Capital e ideología. Barcelona: Editions du Seuil.

Pineda, I., Martínez, L., Bedoya, D., Caparroso, P. y Rojas, J. (2006). Plan de Manejo. Parque Nacional Natural Corales del Rosario y San Bernardo. Recuperado de http:// www.parquesnacionales.gov.co/portal/wp-content/uploads/2013/12/Corales.pdf

Piñeros, S. (2017). Tourism gentrification in the cities of Latin America: The socio-economic trajectory of Cartagena de Indias, Colombia. En Tourism and Gentrification in Contemporary Metropolises: International Perspectives (pp. 75-103). Taylor and Francis. https://doi.org/10.4324/9781315629759

PNUD (2011). Colombia rural, razones para la esperanza. Recuperado de http://www. co.undp.org/content/dam/colombia/docs/DesarrolloHumano/undp-co-resumen_ ejecutivo_indh2011-2011.pdf

Posada, B. y Henao, W. (2008). Diagnóstico de la erosión en la zona costera del Caribe colombiano ( $\mathrm{N}^{\circ}$ 13; Publicaciones Especiales). Recuperado de http://www.invemar. org.co/redcostera1/invemar/docs/605220080501_AErosionCaribeContinentalColombia.pdf

Ramos, A. y Prideaux, B. (2014). Indigenous ecotourism in the Mayan rainforest of Palenque: empowerment issues in sustainable development. Journal of Sustainable Tourism, 22(3), 461-479. https://doi.org/10.1080/09669582.2013.828730

Rioja, L., Benítez, J. y Hernández, R. (2019). Representación social y políticas públicas en materia de turismo: los casos de los Centros Integralmente Planeados de Cancún, Litibú, e Ixtapa-Zihuatanejo, México. El Periplo Sustentable, 37, 92-121. https://doi. org/10.36677/elperiplo.v0i37.9216

Rius-Ulldemolins, J. y Jiménez, L. (2016). Culture, urban transformation and citizen empowerment against gentrification. Comparison between the case of Gethsemane (Cartagena de Indias) and Raval (Barcelona). Eure, 42(126), 97-122. https://doi. org/10.4067/S0250-71612016000200005

Rivera, M. y Rodríguez, L. (2012). Turismo responsable, sostenibilidad y desarrollo local comunitario (Universidad de Córdoba, ed.). Recuperado de https://dialnet.unirioja.es/ servlet/libro? codigo $=525510$

Rojas, H. (2009). Entre lo ideal y lo real; ¿los cambios en los enfoques propuestos de turismo. Cuadernos Desarrollo Rural, 6, 145-171. Recuperado de https://www.oalib. com/paper/971496\#.YTDqdp1KhPY

Saba, M., Lizarazo-Marriaga, J., Hernández-Romero, N. y Quiñones-Bolaños, E. (2019). Physico-mechanical characterization of the limestone used in Cartagena walls and a proposal for their restoration process. Construction and Building Materials, 214, 420-429. https://doi.org/10.1016/j.conbuildmat.2019.04.170

Saba, M., Quiñones-Bolaños, E. y Martínez, H. (2019). Impact of environmental factors on the deterioration of the Wall of Cartagena de Indias. Journal of Cultural Heritage. https://doi.org/10.1016/j.culher.2019.03.001 
Sánchez, D. (2013). Alambre de púas en Playa Blanca (Issue 78). Centro de Investigación y Educación Popular/Programa por la Paz. Recuperado de https://www.cinep.org.co/ publicaciones/PDFS/20130501c.alambre_playa78.pdf

Schulte, S. (2003). Guía conceptual y metodológica para el desarrollo y la planificación del sector turismo. En CEPAL-Serie Manuales (ILPES). Recuperado de http://repositorio.cepal.org/bitstream/handle/11362/5589/1/S2003705_es.pdf

Serge, M. (2010). Desarrollo y conflicto. Territorios, recursos y paisajes en la historia oculta de proyectos y políticas (Universida). Recuperado de https://www.jstor.org/ stable/10.7440/j.ctt18pkdg7

Siegert, L. (2006). Análisis antropológico del impacto del turismo en las poblaciones raizales en Santa Ana, isla de Barú [Universidad de los Andes]. Recuperado de https://repositorio.uniandes.edu.co/bitstream/handle/1992/25903/u281819. pdf? sequence $=1$ \&isAllowed $=y$

Stem, C., Lassoie, J., Lee, D. y Deshler, D. (2003). How 'eco' is ecotourism? a comparative case study of ecotourism in Costa Rica. Journal of Sustainable Tourism, 11(4), 322347. https://doi.org/10.1080/09669580308667210

Tang, Z. (2015). An integrated approach to evaluating the coupling coordination between tourism and the environment. Tourism Management, 46, 11-19. Recuperado de https://doi.org/10.1016/j.tourman.2014.06.001

Tao, T. y Wall, G. (2009). Tourism as a sustainable livelihood strategy. Tourism Management, 30(1), 90-98. https://doi.org/10.1016/j.tourman.2008.03.009

Torres, R. (2003). Linkages between tourism and agriculture in Mexico. Annals of Tourism Research, 30(3), 546-566. https://doi.org/10.1016/S0160-7383(02)00103-2

Turner, B., Kasperson, R., Matson, P., McCarthy, J., Corell, R., Christensen, L., Eckley, N., Kasperson, J., Luers, A., Martello, M., Polsky, C., Pulsipher, A. y Schiller, A. (2003). A framework for vulnerability analysis in sustainability science. Proceedings of the National Academy of Sciences of the United States of America, 100(14), 8074-8079. https://doi.org/10.1073/pnas.1231335100

Unesco (n.d.). UNESCO World Heritage Centre - World Heritage List. Retrieved December 6, 2018. Recuperado de http://whc.unesco.org/en/list/

UNWTO (2017). Making tourism a tool to fight poverty: ten years of the ST-EP Initiative (pp. 1-20). UNWTO. Recuperado de https://www.unwto.org/archive/global/ publication/making-tourism-tool-fight-poverty-ten-years-st-ep-initiative-0

Vianchá, Z. (2021). Configuration of tourist destinations and land use. Review of drivers and implications. Investigaciones Turísticas, 21, 46-66. https://doi.org/10.14198/ INTURI2021.21.3 